\title{
10. Policy development and strategic implications
}

\subsection{RII INCENTIVES AND PERFORMANCE ASSESSMENT}

The previous chapters were mainly concerned with analysis, appraisal and assessment. This chapter focuses its attention on issues of allocation and accountability - the policy dimension of RII enhancement programming. How should public funds be distributed to universities and their partners?

As discussed in the preceding chapters, innovation systems are complex and dynamic social systems. Chance may play a major role in whether specific university actions contribute to major innovations. RII successes and failures are therefore hard, if not impossible, to predict or foresee. What works at a specific university or in a particular region may not work at another university or region. Their RII-related infrastructures, capacities, processes are therefore time-dependent and context-dependent. This does not mean RII outcomes are beyond the scope of policy interventions, or that RII funding programmes are futile; universities with a region-centric portfolio of RII pathways and dedicated strategies to create RII with those facilities, enjoy a much larger probability of success. Supportive regional framework conditions, with dedicated EU funding, can make a big difference in terms of boosting RII capacity and generating RII.

Many universities in Europe could contribute more to innovation systems within their home town, metropolitan area or surrounding region. They should sharpen their focus on creating local value, where RII-oriented activities could either kick-start new initiatives, or act as a catalyst or accelerator of ongoing efforts within universities towards regional economic development. The EU policy documents discussed in section 1.2, such as the policy recommendations of the 'LAB - FAB - APP' report (Lamy et al., 2017) and the report by the RISE high-level expert group (European Commission, 2019b, p. 83), convey a sense of urgency to act by implementing RII-promoting incentives and funding systems that target universities within the EU.

Other high-profile stakeholders in Europe's higher education sector have also expressed their opinions. The EUA and CESAER issued a series of 
general recommendations for regional, national, and European policymakers as part of their views on the future of universities within regional innovation systems (EUA, 2018; CESAER, 2018; Reichert, 2019). Their statements exemplify and amplify the recurring request from the higher education sector, as well as its stakeholders, to develop a dedicated EU stream of sustainable, longer-term funding for innovation activities within universities.

But how to design such policy instruments, especially at the EU level, to deliver an RII agenda for universities in Europe? As a result of historical developments and national governance arrangements, many of these universities enjoy a considerable amount of organisational autonomy. This imposes significant limits on regional, national and European governments or other policymaking actors to influence or steer universities towards regional engagement and RII. However, these universities are also dependent on funding from external sources, which suggests three possible ways for funding-based incentive systems that European, national or regional governments could implement: (1) innovation performance-based funding; (2) innovation performance contracts which make the positive assessment of a strategy for improving RII performance or a particular aspect such as university-business collaboration a condition for funding, and (3) project funding. ${ }^{1}$ Each of these three funding instrument types could, in principle, contribute to the policy-driven allocation of additional funding for regional innovation objectives. EU funding could be supplemented by the Member States, if considered useful by national or regional governments. All three could probably rely, in one way or another, on an RII framework for assessment of proposals and the monitoring and evaluation of RII performance.

At present the RII assessment framework is not (yet) implemented at the $\mathrm{EU}$, nor the national or regional level. If policymakers choose to implement it, they can best do it in the form of policy experimentation based on a Theory of Change, as described in section 3.2, underpinning the assumption that RII-oriented inventions at universities may significantly contribute to change in regional innovation systems or interactions between universities and

1 'Project funding' refers to funding of a group or an individual to perform an R\&D activity limited in scope, budget and time, normally on the basis of the submission of a project proposal describing the research activities to be done (Van Steen, 2012). 'Institutional funding', organisational level funding, is attributed to a research-performing organisation (either a university, another higher education institution or a research organisation), with no direct selection of R\&D projects or programmes and for which the organisation has more or less freedom to define the research activities to be performed. Institutional funding can be provided as a block grant or in a competitive manner, e.g. on the basis of ex post performance assessments (performance-based funding) or in the form of performance contracts in which a university agrees with a funding body to meet certain agreed upon objectives. 
regional partners. Adopting an experimentation mode allows implementation to proceed even if there is still uncertainty about the immediate prospects of a solution or, ultimately, the anticipated positive outcomes. In this particular case, RII-promoting initiatives and incentive systems can act as a 'strategic niche' (Schot and Geels, 2008) where such a system change can occur, learning from the self-appraisal reporting and self-assessment, to create new interactive regimes and associated 'regional science and innovation landscapes'. Such a Theory of Change driven approach is also more amenable to effective implementation, which requires a shared understanding of the problem by all major stakeholders, the existence of an appropriate policy environment and acceptance of the proposed policy solution by decision makers (Flanagan et al., 2011).

Well-designed incentive instruments may help tackle some of the implementation challenges identified in previous chapters of this book, for example to counter-balance the tendency among universities to tell only success stories and downplay their failures or less positive achievements. If properly embedded in a university's organisational framework, such incentives may stimulate universities to also identify what does not work (well enough) and develop ways to address these problems or related future challenges. Acknowledging and analysing failures and obstacles may help to adopt strategies to overcome bottlenecks or shortcomings. RII incentive systems and associated assessment frameworks will then also become organisational self-learning tools that offer opportunities for retrospective and future-oriented enquiry within the university.

In order to develop incentive systems there needs to be a set of design principles in place concerning their technical feasibility and attractiveness for applicants, in which incentives should:

- be tied to clear objectives which can be measured/assessed;

- fit within existing or new legal and regulatory frameworks of the EU, its Member States and/or regional authorities;

- align with existing or new funding structures in the EU 2021-2027 programmes, such as the co-financing arrangements within the European Regional Development Fund (ERDF);

- ensure that the proposed application procedure is as accessible and user-friendly as possible;

- make RII funding arrangements sufficiently attractive for senior operational staff at HEIs (heads of departments, professors, principal investigators, etc.) and/or regional external partners;

- promote and support the development of shared interests and joint activities between HEIs and regional partners;

- enable effective cross-border collaboration and joint activities. 
Complying with these principles is probably difficult, if not impossible; trade-offs between feasibility and attractiveness will have to be made.

The next section discusses some potential ways in which the RII assessment framework could be implemented. Exploring the above-mentioned three types to RII funding, sections 10.3 to 10.5 discuss potentially relevant instruments at the EU level. ${ }^{2}$

\subsection{POTENTIAL TYPES OF FUNDING INSTRUMENTS}

Innovation performance-based funding is understood as the allocation of institutional funding on the basis of ex post assessments of innovation performance (Hicks, 2012). At the national level, European governments have implemented a broad range of different types of research performance-based funding systems, some of which have been implemented in ways that connect (research) performance and socio-economic impact of institutional funding allocation (Jonkers and Zacharewicz, 2017).

A high-profile example of such an instrument is the UK Research Excellence Framework in the United Kingdom (UK), where socio-economic impact of research is assessed through expert panels on the basis of case studies of individual research impacts (Derrick, 2018). Other funding instrument types include innovation-related metrics in formulas that are used for allocating institutional resources between universities. Both types of funding systems are not without their critics. The UK system has been criticised for, among other reasons, putting a large burden on universities, academic staff and evaluators (e.g. Martin, 2011; Smith et al., 2020). The extent to which the case studies succeed in capturing significant impacts is also contested. Because socio-economic impacts of research tend to take a long time to develop and are subject to a high degree of chance, only a restricted selection of evidence-rich success stories will be submitted for assessment. Mechanistic funding formulae based on a limited set of imperfect innovation-related indicators on the other hand, may provide perverse incentives while failing to stimulate the promotion

2 There are other approaches through which the EU can support the development of innovation systems around universities such as InvestEU, the recovery plan and the just transition funds. Given the nature of these instruments, it is considered less likely that they will directly make use of the RII analytical framework. For the same reason we do not cover the important RII funding for addressing societal challenges and industrial competitiveness in Horizon Europe, the Marie Curie Actions or the ERC. This lack of coverage in this book by no means denies their importance in the development of knowledge, capabilities and human capital developments in universities and their regions. 
of real improvements in university impact performance. RII performance may simply be too complex to capture in this manner at present.

Jonkers et al. (2018) initially suggested tying an RII assessment framework's 'narrative with numbers' approach to an innovation performance-based funding system, on the assumption it could help overcome at least some of the above-mentioned challenges. University level, indicator-supported, case studies assessed by expert panels could offer, they argued, both a baseline and a yardstick for improvement that could inform the allocation of institutional funding to universities. By making assessments university and region specific and by relying on 'narrative with numbers' it could allow tailored incentives, while overcoming some of the problems inherent in a narrow focus on a limited set of key performance indicators alone.

However, there are practical downsides to tying this kind of assessment framework to an innovation performance-based funding approach. Especially in view of potential funding allocation decisions based on summative ex post assessments, universities have a clear incentive to present case studies focused primarily on success stories, presenting their accomplishments in as positive a light as possible. Expert panels would, without considerable additional research of their own (on-site visitations and fact-finding missions), be challenged to critically assess this material. Even following a further improvement of the RII assessment framework, the universities developing such case studies would have little incentive to engage in a critical introspection and self-analysis of the barriers, challenges, reasons for failures and opportunities to improve the potential they have for contributing to their innovation ecosystem.

While an appropriately designed performance-based funding system might overcome some of these practical challenges, there may be other types of instruments that are more suitable to help universities increase their RII potential. Performance contracts are, in contrast to performance-based funding, a type of ex ante funding instrument like project funding. Funding is based on bilateral agreements between the funder and the university, which specifies performance targets that the university promises to deliver in the future and the budget that the university will receive in return. In such performance contracts, the university formulates its ambition in consultation with the funding authority - with or without consultation of other stakeholders such as regional authorities, regional industry or civil society actors. A university may be given a financial penalty if objectives or targets are not met (Jongbloed et al., 2018). Innovation performance contracts, between individual universities and their regional or national funders, have the advantage of customisation and contextualisation. Dedicated contracts provide policymakers and funders flexibility to tailor their agreements to the mission, vision and strategy of individual universities, while taking into account the specificities and needs of the regions in which these organisations operate. Such contracts enable 
funding that addresses university-specific regional priorities, organisational challenges, resource constraints or performance targets. Performance contracts could be limited to the university's success in achieving specific and agreed quantitative targets. However, by assessing the university on the basis of its success in realising a university-level theory of change, government actors could also incentivise measures, investments and organisational changes that raise the RII potential of their universities.

A number of European countries or regional governments have implemented performance contracts with universities over recent decades, including: Austria, Denmark, Finland, Germany (e.g. North Rhine Westphalia), Ireland, the Netherlands, and Scotland (Jongbloed et al., 2018). In addition to strengthening the strategic dialogue between universities and regional, national and EU policymakers and to promote horizontal collaboration between different actors, such contracts can help improve accountability and transparency by helping to inform policymakers and the general public about the university's performance (Jongbloed et al., 2018; OECD/EU, 2018).

The feasibility of such contracts will depend on political decision-making, while their design and ultimate implementation will have to comply with the legislative and regulatory systems of national higher education sectors as well as align with system governance practices. The chances of success are larger the more the funding scheme is in line with these national system-level parameters, targeted at regional demand for partnering with local universities, and sensitive to the absorptive capacity of those partners.

Project funding, such as in the EU Framework programme or the ERDF, as well as a myriad of national programmes, is currently the prevalent mode of funding research-related RII activities in universities. The currently available types of project funding, that by its nature is uncertain, time-bound, and scope-limited, may be insufficient for supporting strategic initiatives at the university level. Some resource-rich universities that saw RII as a strategic objective resorted to using other organisational resources to allow for sustainable support of such activities (see e.g. Appendix D - Technical University of Turin). Projects would need to be large, long term and flexible enough to allow universities to make major improvements to their organisational performance.

Funding RII-support projects will no doubt remain an important part of the RII-funding instruments employed at the regional, national and European level as targeted smaller projects continue to have substantial potential for improving RII capacities and competences. As discussed in the next section, European policymakers could seek to leverage new and existing regional, national and European RII project funding instruments to enhance the potential success of university-level performance contracts, notably by tying the eligibility for receiving funding from specific instruments to the existence of a performance contract. 
The RII assessment model could be used to support funding to any of the three above funding instrument types at the regional, national, or European level. It will be challenging to assemble expert panels who combine the required degree of independence and expertise at the regional and even national level (see section 9.3). The EU Commission, with its experience in designing and running the Framework programme and co-managing the ERDF, could contribute to the creation of a pool of such experts on which regional and national authorities could draw if the framework would be implemented at those levels.

As for the European policy environment, a new multi-annual financial framework has started in 2021 with three elements that could help implement the RII assessment model:

- The ERDF and the Skills for Smart Specialisation specific objective (European Commission, 2018c);

- The Horizon Europe programme for research and innovation (European Commission, 2018d);

- The Erasmus + programme for education, training, youth and sport (European Commission, 2018e).

The next three sections explore whether and how the ERDF and centrally managed EU programmes, including Horizon Europe and Erasmus + , could be linked to a further elaboration and eventual implementation of the RII analytical framework during the financial period 2021-2027.

\subsection{EU FUNDING OPTIONS: EUROPEAN REGIONAL DEVELOPMENT FUND}

The European Commission will channel $€ 193$ billion $^{3}$ in the next planning period (2021-2027) through the ERDF which makes it one of the biggest streams of EC funding. Between $35 \%$ and $60 \%$ of the ERDF will deal with innovation, digitisation and SME-related activities, under the 'Smarter Europe' Policy Objective. In its funding of innovation-related activities, the ERDF tends to focus on the diffusion and exploitation of existing knowledge and technologies to support the innovation system in those regions within EU Member States where it is most needed. Universities are one of the sources of local knowledge, and sometimes technologies, in such regions. Furthermore,

3 The $€ 193$ billion reflects the political agreement between the Council and the Parliament of 8 December 2020. At the time of writing, this political agreement was still subject to formal approval by the European Parliament and Council. https://ec .europa.eu/commission/presscorner/detail/en/qanda_20_2381. 
they can provide highly qualified human resources that allow businesses to adopt new technologies. The need to match investments in research and innovation with related investment in skills has now been recognised as vital for technology diffusion (European Commission, 2017b), which hitherto had been a weakness of the EU funding framework for smart specialisation (Edwards et al., 2017) and indeed by innovation policy as a whole (Borrás and Edquist, 2015). Some regions had already recognised this gap in their smart specialisation strategies and used the European Social Fund or other sources of national funding to make investments in human capital to match their smart specialisation priorities (Campillo et al., 2017; Pinto et al., 2021). However, post 2020 the ERDF will make such investments under the rubric of 'Skills for Smart Specialisation, Entrepreneurship and Industrial Transition'. ${ }^{4}$ The ERDF could therefore be relevant for RII-related activities where funding is meant to support regional innovation system development based on smart specialisation strategies (Foray and Goenaga, 2013; Foray, 2014; 2018; 2019). RII funding could help build and expand regional research and innovation capacities, and incentivise entrepreneurial processes in the region.

The ERDF has so far placed much more emphasis on policy interventions targeted at business enterprises, the RII 'demand side', than attempts to directly change the RII behaviour of 'supply side' universities. Higher education is predominantly a national competence where, as mentioned above, national legislation and regulations limit the space for implementing EU policies. However, within the EU's Cohesion Policy, ERDF co-funded Operational Programmes can help create or support firms, across any economic sector, that are likely to benefit from local universities, either in terms of human resources, skills, knowledge transfer or R\&D cooperation. If the ERDF expands and strengthens the demand for inputs from universities, especially in the EU's economically lesser developed regions, it will become more important to increase the RII potential and performance of local universities. In doing so it will improve the proper functioning of the regional innovation systems of which they are part, to help facilitate and motivate local firms to innovate (Kempton et al., 2013; Radosevic, 2017). While not its prime target, universities have benefitted from ERDF funds during the past programming period, ${ }^{5}$ especially those that played

4 Smart specialisation is no longer a one-off ex ante conditionality but an ongoing 'enabling condition'. It will also have a reinforced weight in the coming Cohesion Policy: smart specialisation will guide investment decisions within a broader policy area than in the past, including: R\&I, digitalisation, SMEs support and skills development.

5 Many universities in the Eastern and Southern EU Member States show a significant increase of academic research publications over the last few years that acknowl- 
an active role in developing smart specialisation strategies (Kempton et al., 2013; Edwards et al., 2017).

In contrast to Horizon 2020 and Erasmus + , the ERDF operates under shared management with the Member States. The EC defines the overall framework in terms of objectives and funding allocation. However, it negotiates funding on a Member State level or the within-country regional level (not at the level of projects or individual stakeholders). The Member States define the content and geographical scale of the different 'operational programmes' in line with the Common Provisions Regulation (CPR) (European Commission, 2018c). The EC forms partnership agreements with the competent regional and local authorities and regional/local stakeholder representatives. Articles 12 and 13 of the CPR stipulate that the Member States shall establish a performance framework, in order to monitor, report and evaluate programme performance during its implementation, and contribute to measuring the overall performance of EU Funds. This framework includes output and result indicators linked to the specific ERDF objectives as well as milestones to be achieved by 2024 and 2029. Managing authorities could work with national and regional governments and use performance contracts with universities to help meet certain ERDF milestones.

If the EIT regional funding option, discussed in more detail in the next section, is successful in enhancing regional innovation performance, it may open an ERDF door for implementing RII-related performance contracts between regional actors and universities on concrete ERDF-supported improvements of regional innovation systems. The amount of RII-support funding that can be allocated would need to be established by a fair, equitable, and verifiable calculation method based on statistical data, other objective information or an expert judgement, which would be verified with historical performance data.

The challenge for the 2021-2027 funding period is to improve on the current ERDF/Smart Specialisation funding system, which depending on the economic development level of the region, caps the EU co-financing share between $50 \%$ and $75 \%$. While there are some universal mechanisms that can be adopted across the whole of the EU, the effectiveness of incentives is also contingent on national or local circumstances, especially on how universities are funded and regulated within their national higher education system, and the region's industrial structure and governance system.

edge ERDF support in their funding grant acknowledgements (Tijssen and Van Wijk, 2020). 


\subsection{EU FUNDING OPTIONS: HORIZON EUROPE AND THE EUROPEAN INSTITUTE OF INNOVATION AND TECHNOLOGY}

The EU has directly supported research and innovation over the last four decades with its series of Framework Programmes. Their budget has increased from about $€ 4$ billion in the first framework programme to nearly $€ 80$ billion in Horizon 2020, which ran until 2021. The successor programme, Horizon Europe, will have a €95.5 billion budget over the 2021-2027 funding period. ${ }^{6}$

The content and approach of the Framework Programme series has evolved over time to include commercial research and innovation as well as academic research. In Horizon 2020, funding for industrial leadership and societal challenges accounted for double the budget of the funding for excellent science. The first pillar of Horizon Europe combines the different actions on excellent science while the second pillar combines industrial innovation and global challenges into one pillar, as exhibited in Figure 10.1.
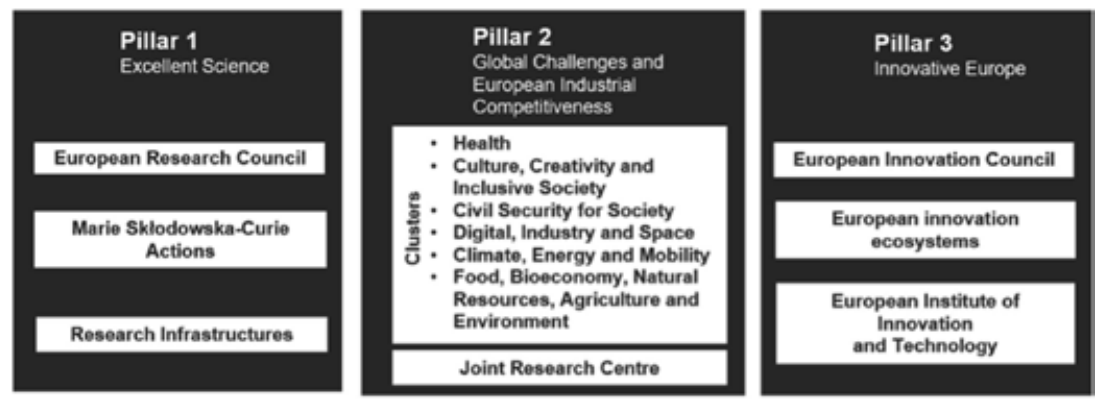

Widening Participation and Strengthening the European Research Area

Widening participation and spreading excellence

Reforming and Enhancing the European R\&I system

Figure 10.1 Programme structure of Horizon Europe

Horizon Europe allows for putting more emphasis on innovation, through a new pillar on Innovative Europe, which is of crucial relevance to the RII

6 The $€ 95.5$ billion reflects the political agreement between the Council and the Parliament of 10 December 2020. At the time of writing, this political agreement was still subject to formal approval by the European Parliament and Council. https://ec .europa.eu/commission/presscorner/detail/en/IP_20_2345. 
assessment framework. With an overall budget of around $€ 13.6$ billion, ${ }^{7}$ this pillar aims to bring innovation faster to the market, while recognising that innovation is complex and the result of investments at different stages of the development cycle and dependent on dynamic innovation ecosystems. ${ }^{8}$

Part of the third pillar of Horizon Europe aims at "developing an effective innovation ecosystem at EU level, and encouraging cooperation, networking, and the exchange of ideas, funding and skills among national and local innovation ecosystems" (European Commission, 2018b). As a new instrument, its operationalisation will become clearer over time. ${ }^{9}$ It provides a policy environment in which an RII analytical framework can be explored and potentially linked to 'experimental' funding. The pillar's 'European Innovation Ecosystem' instrument will have a budget of $€ 527$ million $^{10}$ and will co-fund joint innovation programmes delivered by national bodies, including those that promote knowledge transfer and university-business cooperation.

Of all programmes within the Horizon Europe funding portfolio, the European Institute of Innovation and Technology (EIT) has perhaps the most potential to make use of the RII analytical framework, since the EIT's strategy is based on the 'Knowledge Triangle' approach, which brings together

\footnotetext{
7 Source: personal contact with DG RTD. The exact figures of this part of the political agreement between the Council and the Parliament of 10 December 2020 had not yet been published at the time of writing. The political agreement was also still subject to formal approval by the European Parliament and the Council.

8 In September 2020, the European Commission introduced the 'ERA Hubs' initiative, to create regional organisations designed to boost regional research and innovation systems in Europe and provide better access to the results elsewhere within the European Research Area. The exact form which the ERA Hubs may take still need to be announced, but they will be similar in nature of the Digital Innovation Hubs. It could be explored to what extent the RII framework can help inform the analysis or assessment of participating partners in these Hubs.

9 Being a new funding instrument, its operationalisation and implementation will become clearer over time, a process that will start with a European Innovation Council Forum, bringing together all the EU Member States but also associated Horizon Europe countries, in order to help develop the ecosystem approach. This Forum will discuss innovation-friendly regulation as well as coordination of underpinning national innovation programmes, which could include a discussion on how RII assessment may be linked to institutional funding. Between October 2019 and February 2020, the Commission already organised a series of consultation workshops on this future pillar of Horizon Europe (European Commission, 2020).

10 Source: personal contact with DG RTD. The exact figures of this part of the political agreement between the Council and the Parliament of 10 December 2020 had not yet been published at the time of writing. The political agreement is also still subject to formal approval by the European Parliament and the Council.
} 
research, education and enterprise. ${ }^{11}$ Pending final confirmation of the political agreement between Council and Parliament, the EIT will have a budget of nearly $€ 3$ billion under Horizon Europe, representing a $25 \%$ or $€ 600$ million increase compared to the previous funding period. ${ }^{12}$

The EIT was created in 2008, partly in response to missing the goals of the Lisbon Agenda, which aimed to position the EU within the global knowledge economy. European policymakers wanted to replicate vanguard organisations found elsewhere in the world that facilitate entrepreneurship and the rapid market introduction and development of innovative ideas (Reillon, 2016). In contrast to individual organisations located in just one place, the EIT was operationalised through trans-national Knowledge and Innovation Communities (KICs). These KICs are independent legal entities that enjoy a large degree of autonomy in terms of strategy and choice of activities from the EIT headquarters in Budapest (Hungary). Composed of firms, research centres, higher education institutions as well as cities, regions and NGOs, eight KICs have been launched over the last decade. They fund investments in education, research, and entrepreneurship, which are intended to work together in a triangular mode. While many universities host KIC co-location centres, ${ }^{13}$ others take part in activities under the EIT Regional Innovation Scheme, which aims to spread the impact of KICs more widely across Europe in countries and regions that lag behind in terms of innovation performance. At the same time universities have the potential to bring together local stakeholders active in a region's smart specialisation priorities (Edwards et al., 2017) and therefore they are well placed to bring together innovation communities and combine sources of funding (Ozbolat et al., 2019).

While the EIT was created to pursue excellence in the integration of innovation-driven research, entrepreneurial education and entrepreneurship, there has been increasing pressure on KICs to extend their impact beyond the immediate KIC partners, thus stimulating innovation on a wider scale. This is partly the rationale and motivation behind proposals for the EIT to engage in capacity building activities for innovation in HEIs, as part of its Strategic Innovation Agenda from 2021 to 2027 (European Commission, 2019c). While

11 The knowledge triangle originated as part of the European Union's Lisbon Strategy (Cervantes, 2017; Soriano and Mulatero, 2010). It is a conceptual framework for analysing and understanding knowledge creation processes that depend on productive interactions between education, research, and innovation. The framework highlights the need for an integrated approach across education, research, and innovation policies.

12 https://ec.europa.eu/commission/presscorner/detail/en/ip_21_207.

13 Co-location centres act as nodes that bring together all the main KIC activities in one physical place. 
managed by the KICs, a large share of the activities will benefit universities that are not currently KIC partners. This can potentially allow for learning between universities from different parts of Europe, and between those that are more and less developed. According to the Commission proposal, the details of activities under this pilot action will be developed in the first three years, but the Council has suggested the following (Council of the European Union 2020): $:^{14}$

- the exchange and implementation of best practices in knowledge triangle integration (including organisational learning, coaching and mentoring);

- the development of action plans on how to address identified needs in areas such as innovation management, start-up creation and development, technology transfer including IPR management, people and organisational management and engagement with (local) stakeholders and civil society;

- the implementation of innovation capacity development action plans and their follow-up.

The same proposal suggests that the 'EIT label', which is currently used within the KICs for quality assurance and marketing of master and $\mathrm{PhD}$ degrees, could be extended to those universities involved in capacity-building pilot activities. The label would be particularly useful to build entrepreneurial capacity among students and staff in participating universities, drawing on their recent experience in the KICs.

The EIT-KIC capacity-building action presents a good opportunity to test the RII analytical framework and demonstrate its value for the KICs as well as regional and national authorities. From the KIC perspective, it could be used to improve the regional innovation impact of university partners, which in turn would strengthen other activities within the knowledge triangle. The RII analytical framework is explicitly mentioned in the proposed SIA as a tool that could be used within that action, along with the HEInnovate self-assessment tool (see section 3.1). The RII analytical framework is already used in the co-creation phase of the new initiative to frame the discussions on the categories of activities to be included and on the development of the impact framework for this initiative (inputs, outputs, outcomes, impacts).

Following a further redesign to ensure the framework could guide the development of self-assessments as discussed in Chapter 9, an RII assessment

14 At the time of publication, the decision on the SIA was still in the process of being adopted by the Council of the European Union and the European Parliament, with many proposed amendments. 
framework could be used in a number of ways, but some suggestions to consider are:

- RII self-appraisal could form part of capacity building and training exercises;

- RII assessments could be linked to targeted or increased funding at the strategic level for departments or staff that increase the impact of their university;

- Experts could be contracted to assess the RII of universities not currently members of a KIC;

- Assessments could form part of the process of joining a KIC. Regular RII assessment could form the basis for providing top-up institutional funding to universities in order to improve their RII potential, e.g. through performance contracts.

Policymakers will need to assess the suitability of the RII assessment framework in each of these proposed steps and the most appropriate sequencing and operationalisation.

Using RII assessment within the capacity building action and the mainstream KIC activities could be a mechanism to exploit funding synergies which the KICs have found difficult to explore so far (Ozbolat et al., 2019). This is one of the areas where the links to smart specialisation and the ERDF are underlined in the proposed SIA. KICs could co-finance ERDF investments in the capacity of participating universities to increase their regional impact and guide them in the implementation of ERDF projects aiming at entrepreneurial transformation. This might in the future lead to the adoption of an RII assessment framework within the ERDF. Furthermore, if the framework can help to increase the regional impact of universities involved with the KICs, national authorities may be convinced to use a similar assessment for granting institutional funding within their higher education sector.

\subsection{EU FUNDING OPTIONS: ERASMUS PROGRAMME AND THE EUROPEAN UNIVERSITIES INITIATIVE}

Erasmus has grown to become a dedicated education programme for the European Union, while respecting national policy competences, although the EU only supports competences for education, training and sport. Focused on promoting learning mobility, which the programme has funded since the 1980s, it now includes support for cooperation and partnerships, notably the flagship initiative on European Universities. The Erasmus + programme (2014-2020) had a budget of nearly $€ 15$ billion with three 'key actions': 
learning mobility (key action $1-63 \%$ of budget); cooperation for innovation and good practice (key action 2-28\%); Support to Policy Reforms (key action 3 - 4\%). The Commission's proposal for Erasmus 2021-2027 retains these three key actions, while nearly doubling the overall budget of the programme to more than $€ 26$ billion. ${ }^{15}$

The European Universities initiative was launched in 2017 at the Gothenburg Summit of EU leaders and is intended to help build the European Education Area. This initiative is essentially designed to create trans-national partnerships of universities. The EC hopes that these networks will become sustained alliances, rather than short-term projects that do not outlive the programme funding. While joint curricula and mobility among partnering universities promote the trans-national nature of these alliances, many policy documents underline their role in municipal and regional development, such as in this staff working document:

[European Universities] should operate on the basis of multidisciplinary approaches, allowing students, lecturers and researchers to co-create and share knowledge and innovation. This could help address the big societal challenges and skills shortages that Europe faces. It could also boost the contribution that higher education institutions make to their regions, in particular through their involvement in the development and implementation of Smart Specialisation Strategies. (European Commission, 2018a, pp. 5-6)

The contribution to regional development and smart specialisation is part of a proposal's relevance that evaluators use in assessing applications for Erasmus + funding. This is more explicit in some of the alliances than others when looking at the joint long-term strategies they are required to draw up for the proposal. In implementing these strategies, the RII assessment framework could be used by the alliances to assess their contribution to the cities and regions where the partner universities are located. The initiative is linked to Horizon 2020's 'institutional transformation modules', which in 2020 launched pilot calls exclusively for the selected European Universities. This funding, which amounts to $€ 2$ million over three years, aims to develop the research and innovation dimension of European Universities through institutional change; it does not support implementation of research and innovation projects as such. Examples of relevant activities include implementing frameworks for assessing the impact of partner organisations within their regional innovation systems. While there are no concrete plans to do so at present, in

15 https:/www.europarl.europa.eu/news/en/press-room/20201207IPR93204/ ep-and-eu-ministers-agree-on-erasmus-programme-for-2021-2027. At the time of writing, this agreement still needed to be approved by Parliament as a whole as well as the Council. 
the future this initiative may provide an opportunity to link funding to an RII assessment framework. 